Original Article

\title{
STABILITY INDICATING METHOD DEVELOPMENT AND VALIDATION FOR SIMULTANEOUS QUANTIFICATION OF SORAFENIB AND REGORAFENIB DRUG SUBTANCES BY USING RP-UPLC
}

\author{
VIDYASAGAR CHOPPELLA ${ }^{a^{*}}$, RAGHU BABU K.a, SURESH BADIPATIa, HARITHA GONTHINAa, VENKATA KISHORE \\ CHUKKA $^{\mathrm{a}}$
}

aDepartment of Engineering Chemistry, Andhra University College of Engineering (A), Andhra University, Visakhapatnam, Andhra

Pradesh, India

Email: vidyasagarchoppella@gmail.com

Received: 14 Aug 2019, Revised and Accepted: 24 Oct 2019

\begin{abstract}
Objective: The aim of the research work is to develop and validate a novel, sensitive, specific, rapid, accurate, precise and stability indicating gradient reverse phase ultra-performance liquid chromatography (RP-UPLC) method for the quantitative determination of sorafenib and
\end{abstract} regorafenib drug substances.

Methods: Liquid chromatographic method used for the analysis of the anti-cancer drug substances like sorafenib and regorafenib and method was developed and validated by using efficient chromatographic separation method and was achieved with the use of acquity UPLC system was used consisting of quaternary pump, photodiode array detector an auto injector and on line degasser.

Results: The separation was achieved using acquity UPLC BEH C18, $1.7 \mu \mathrm{m} .2 .1 \times 50 \mathrm{~mm}$ analytical column at $30{ }^{\circ} \mathrm{C}$ employing a gradient elution. Empower software was used for data acquisition. During method validation all the parameters were evaluated as per ICH guidelines, which remained well within acceptable limits. Degradation of the drug substances was found to be stable to acidic, aqueous, basic hydrolysis, thermal hydrolysis and photolytic stress condition and the tests solution of the drug substance was found to be stable up to $24 \mathrm{~h}$.

Conclusion: The results of linearity, precision accuracy and specificity were proved to be within the limits. This method can be employed in routine analysis for simultaneous estimation of sorafenib andregorafenib drug substances in quality formulations and dissolution studies.

Keywords: Regorafenib, Sorafenib, RP-UPLC

(C) 2020 The Authors. Published by Innovare Academic Sciences Pvt Ltd. This is an open access article under the CC BY license (http://creativecommons.org/licenses/by/4.0/) DOI: http://dx.doi.org/10.22159/ijcpr.2020v12i1.36832. Journal homepage: https://innovareacademics.in/journals/index.php/ijcpr

\section{INTRODUCTION}

Anti-Cancer drugs are medicines formulated to treat wide range of cancer. Cancer is the uncontrolled growth of cells that interfere with the growth of healthy cells [1]. The usual treatments of Cancer are surgery, chemotherapy (treatment with anticancer drugs), radiation, or some combination of these methods [2]. Anti-Cancer drugs are targeted to control and treat various Cancer like, Breast cancer, Cervical cancer, Small cell lung cancer, Head and Neck cancer, Ovarian cancer, Hodgkin's and Non-Hodgkin's lymphoma, Oesteosarcoma, Seminomas of testis, Myeloblastic leukemia, Lymphoblastic leukemia etc [3]. Synthesized or procured from natural or synthetic sources for cancer inhibition and cure is known as "chemotherapy" and the drugs are more commonly named as chemotherapeutic drugs [4]. As stated earlier, cancer can be defined as a state where cells or tissues of the body start to divide uncontrollably and evade the normal cell cycle as a result of which progression of large tumors occur, and the tumorous cells by the mechanism of metastasis may invade the neighboring normal tissues of the body causing serious implications [5]. Keeping this in mind cancer drugs has been designed to slowly act on the cancerous cells and halt their progression by suppressing them through various molecular mechanisms [6].

\section{Sorafenib}

Sorafenib (SFB) (4-pyridine 2-carboxylic acid methylamide 4methylbenzenesulfonate) is a multikinase inhibitor that has antiangiogenicand antitumor activity [7]. Sorafenib prevents C-RAF, B-RAF, c-KIT, FLT-3, platelet-derived growth factor receptor-b (PDGFR-b), and vascularendothelial growth factor receptor (VEGFR) 1,2 , and 3 , and is approved for the treatment of advanced renal cell carcinoma and hepatocellular carcinomain 2005 and 2007, respectively [8]. SFB is currently being investigatedfor the treatment of other solid tumor malignancies and acute myelogenousleukemia
[9]. SFB drug was approved for the treatment of primary kidney cancer and advanced primary liver cancer [10].<smiles>CNC(=O)c1cc(Oc2ccc(NC(=O)Nc3ccc(Cl)c(C(F)(F)F)c3)cc2)ccn1</smiles>

Fig. 1: Chemical structure of Sorafenib

\section{Regorafenib}

Regorafenib (RG) is an orally administrated tyrosine kinase inhibitor and it is used for the second-line therapy in intermediate or for advanced hepato cellular carcinoma patients [11]. RG has also been approved for the treatment of colorectal cancers and advanced gastrointestinal tumors [12]. In patients with advanced solid tumors, the recommended oral dose of RG is $160 \mathrm{mg}$ [13]. The pharmacokinetic properties of RG have been previously associated with differential expression of certain transporters and enzymes [14]. However, the exact mechanisms by which the drug is taken up into hepatocytes and how its metabolites are processed still remain 
largely unknown. Previous investigation has suggested that regorafenib undergoes extensive hepatic metabolism through two competing pathways involving CYP3A4 and UGT1A9, which result in the formation of regorafenib-N-oxide (M2), N-desmethylregorafenib-N-oxide (M5) and regorafenib-N- $\beta$-glucuronide (M7; RG) [15].<smiles>CNC(=O)c1cc(Oc2ccc(NC(=O)NC3C=C(C(F)(F)F)C(Cl)=CC3)c(F)c2)ccn1</smiles>

Fig. 2: Chemical structure of regorafenib

\section{Experimentaland preparation of solutions}

\section{Materials and methodology}

The reference samples of sorafenib and regorafenibdrug substances were gifted from Bulk drug manufacturing Industry in Hyderabad, Telangana. Formic acid, Acetonitrile, methanol, Sodium hydroxide and Hydrochloric acid purchased from Merck, India and pure milli-Q water was used with the help of Millipore purification system. Hydrogen peroxide was acquired from Sigma Aldrich.

A Novel, sensitive, specific, rapid accurate precise and stability indicating gradient reverse phase ultra-performance liquid chromatography (RPUPLC) method was developed and validated for the quantitative determination of sorafenib and regorafenib drug substances. Liquid chromatographic method used for the analysis of the anti-cancer drug substances like sorafenib and regorafenib and method was developed and validated by using efficient chromatographic separation method and was achieved with the use of acquity UPLC system was used consisting of quaternary pump, photodiode array detector an auto injector and on line degasser. The separation was achieved using acquity UPLC BEH C18, $1.7 \mu \mathrm{m} .2 .1 \times 50 \mathrm{~mm}$ analytical column at $30{ }^{\circ} \mathrm{C}$ employing a gradient elution. Empower software was used for data acquisition. The chromatographic separation was achieved using analytical column by step gradient programme T\% of B: 0.0/5,0.5/5,3.5/98,5.5/98,6/5,7/5 was used at a flow rate of $0.5 \mathrm{mlmin}-1$ with injection volume of $10 \mu \mathrm{l}$ and the detection was done at $262 \mathrm{~nm}$ using PDA detector. Mobile phase A: 1 $\mathrm{ml}$ of formic acid in $1000 \mathrm{ml}$ of milli-Q water, mixed well and sonicated. Mobile phase B: Acetonitrile The retention times of sorafenib and regorafenib drug substances found to be $3.09 \mathrm{~min}$ and $3.2 \mathrm{~min}$ respectively. During method validation all the parameters were evaluated as per ICH guidelines, which remained well within acceptable limits. Degradation of the drug substances was found to be stable to acidic, aqueous, basic hydrolysis, thermal hydrolysis and photolytic stress condition and the tests solution of the drug substance was found to be stable up to $24 \mathrm{~h}$.

\section{Preparation of solutions}

\section{Preparation of mobile phase-A}

Mobile phase is prepared by mixing $1000 \mathrm{ml}$ water with $1 \mathrm{ml}$ of formic acid and sonicated the resulting solution well, degassed it using vacuum filtration through $0.22 \mu \mathrm{m}$ filter.

\section{Preparation of mobile phase-B}

Mobile phase is prepared by mixing $1000 \mathrm{ml}$ Acetonitrile with $1 \mathrm{ml}$ of formic acid and sonicated the resulting solution well, degassed it using vacuum filtration through $0.22 \mu \mathrm{m}$ filter.

\section{Preparation of standard stock solution}

Weighed accurately $40 \mathrm{mg}$ Sorafenib (SOR) and $16 \mathrm{mg}$ of Regorafenib (REG) transferred in to a $100 \mathrm{ml}$ volumetric flask, about $60 \mathrm{ml}$ of diluent added and sonicated to dissolve.

Made up to the mark with diluent, mixed well and sonicated to degas.

\section{Linearity solution preparation}

\section{5\% Standard solution}

$0.5 \mathrm{ml}$ of standard stock solutions was pipetted out andmade up to $50 \mathrm{ml} .(4 \mu \mathrm{g} / \mathrm{ml}$ of Sorafeniband $1.6 \mu \mathrm{g} / \mathrm{ml}$ of Regorafenib).

\section{$\mathbf{5 0 \%}$ Standard solution}

$1 \mathrm{ml}$ of standard stock solutions was pipetted out andmade up to 50 $\mathrm{ml}$. $(8 \mu \mathrm{g} / \mathrm{ml}$ of Sorafenib and $3.2 \mu \mathrm{g} / \mathrm{ml}$ of Regorafenib)

\section{5\% Standard solution}

$1.5 \mathrm{ml}$ of standard stock solutions was pipetted out andmade up to $50 \mathrm{ml} .(12 \mu \mathrm{g} / \mathrm{ml}$ of Sorafenib and $4.8 \mu \mathrm{g} / \mathrm{ml}$ of Regorafenib)

\section{$100 \%$ Standard solution}

$2 \mathrm{ml}$ of standard stock solutions was pipetted out andmade up to 50 $\mathrm{ml}$. (16 $\mu \mathrm{g} / \mathrm{ml}$ of Sorafenib and $6.4 \mu \mathrm{g} / \mathrm{ml}$ of Regorafenib)

\section{$125 \%$ Standard solution}

$2.5 \mathrm{ml}$ of standard stock solutions was pipetted out andmade up to $50 \mathrm{ml}$. $(20 \mu \mathrm{g} / \mathrm{ml}$ of Sorafenib and $8 \mu \mathrm{g} / \mathrm{ml}$ of Regorafenib)

\section{$150 \%$ Standard solution}

$3 \mathrm{ml}$ of standard stock solutions was pipetted out andmade up to 50 $\mathrm{ml}$. $(24 \mu \mathrm{g} / \mathrm{ml}$ of Sorafenib and $9.6 \mu \mathrm{g} / \mathrm{ml}$ of Regorafenib)

\section{Preparation of test sample stock solution}

Average weight was calculated for 20 tablets and an amount equivalent to $40 \mathrm{mg}$ of Sorafenib and $16 \mathrm{mg}$ of Regorafenib was taken into $100 \mathrm{ml}$ volumetric flask. The sample was dissolved in 10 $\mathrm{ml}$ of diluent. The above solution was filtered using HPLC filters. Pipette out $2 \mathrm{ml}$ of the above solution into $50 \mathrm{ml}$ volumetric flask and made up with diluent.

\section{RESULTS AND DISCUSSION}

\section{Method development}

In developing a suitable HPLC method for the quantitative determination ofSOR and REG, the effect of different parameters such as diluent, buffer concentration, organicsolvent for mobile phase composition and other chromatographic conditions werestudied.

Determination of maximum wavelength for sorafenib and regorafenib using PDA detector

The maximum wave length for the sorafenib and regorafenibdrug substances was observed at 262 nmusing PDA detector in RP-UPLC. At $262 \mathrm{~nm}$ sorafenib and regorafenib drug substances both were showing absorbance. With the above mentioned wave length was selected for the estimation of the sorafenib and regorafenib drug substances. Fig. 3 and 4 showing the spectrum ofsorafenib and regorafenib drug substances by PDA detector in UPLC.

\section{System suitability}

Initially system suitability was established for the evaluation of the method before running the sample for the validation parameters. The test was performed according to USP. The standard solutions were prepared as per the proposed method. The results of the system suitability were tabulated in the below table: 1 and Chromatograms of system suitability were shown in fig. 5 


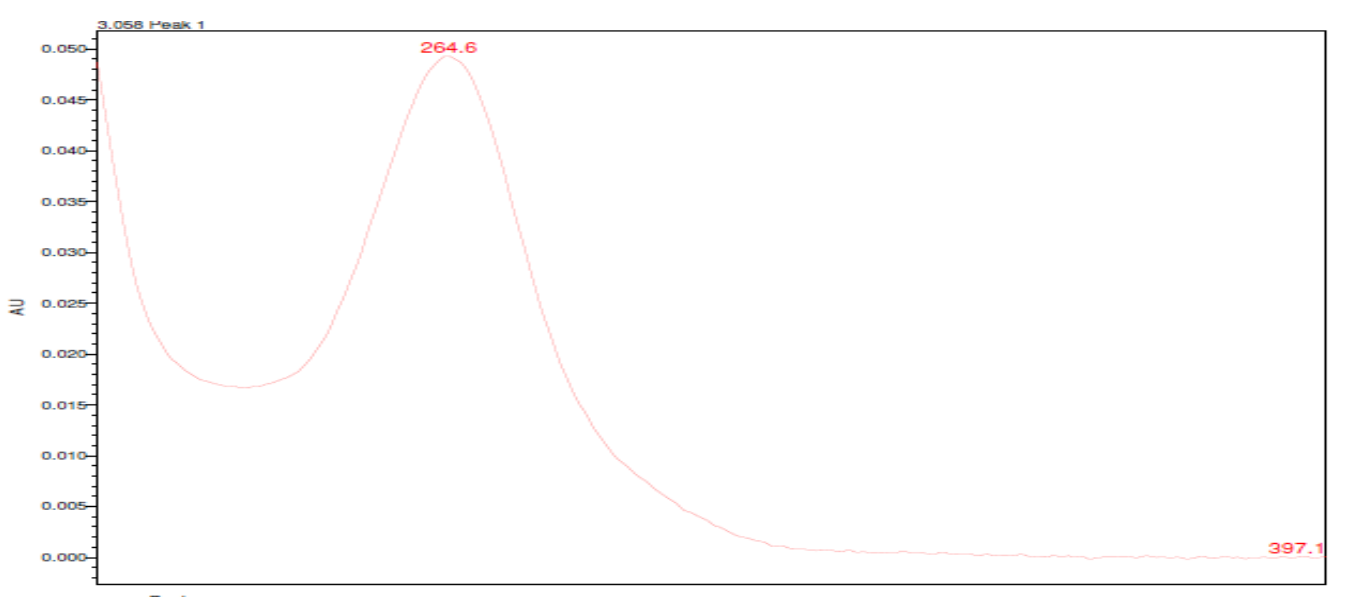

Fig. 3: Spectrum ofsorafenibdrug substances by PDA detector in UPLC

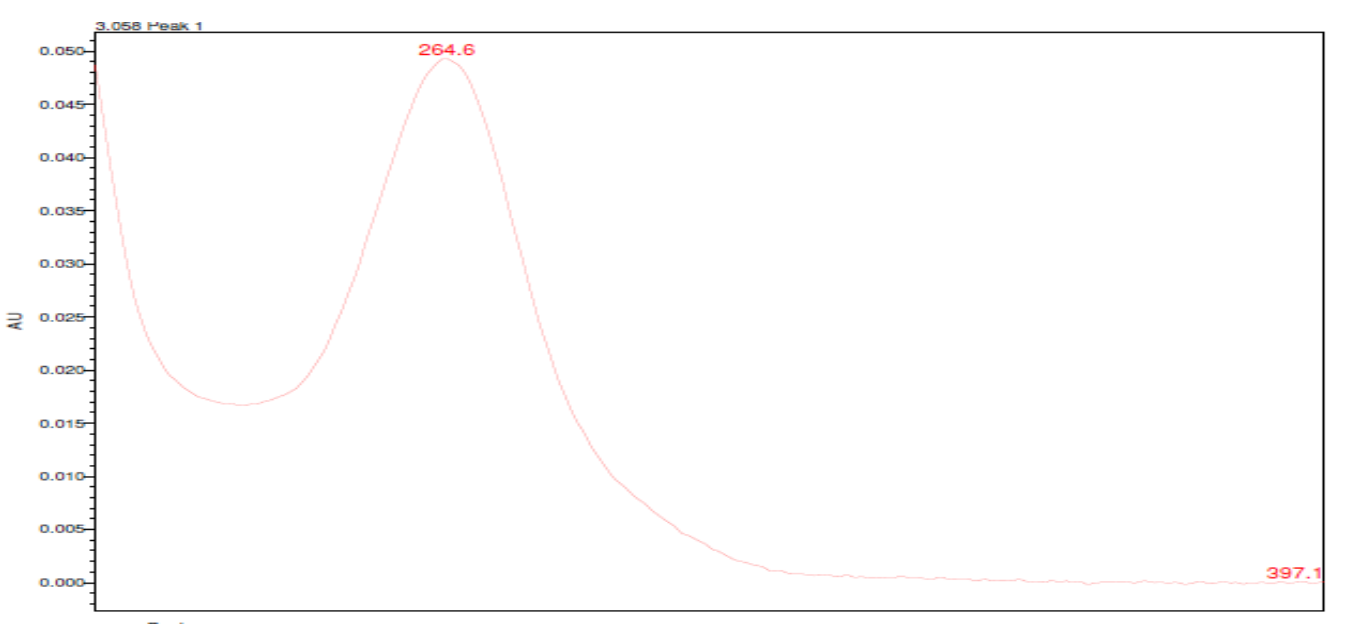

Fig. 4: Spectrum of regorafenib drug Substances by PDA detector in UPLC

Table 1: Results of the system suitability

\begin{tabular}{|c|c|c|c|}
\hline \multirow{2}{*}{ Parameter } & \multirow[t]{2}{*}{ Acceptance criteria } & \multicolumn{2}{|l|}{ Results } \\
\hline & & Sorafenib & Regorafenib \\
\hline USP Plate Count & Not less than 2000 & 128786 & 154334 \\
\hline USP Tailing Factor & Not more than 2.0 & 1.5 & 1.3 \\
\hline Resolution Factor & Not less than 2.0 & - & 3.7 \\
\hline$\%$ RSD for Peak areas of the Drug Substances & Not more than $2.0 \%$ & 0.33 & 0.69 \\
\hline
\end{tabular}

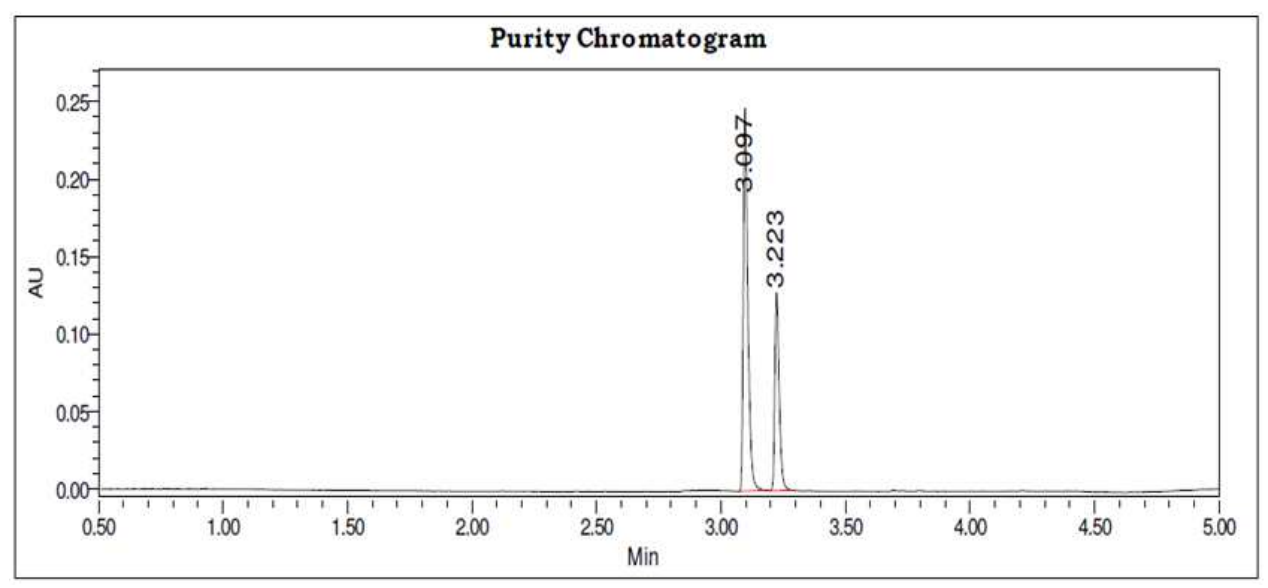

Fig. 5: System suitability UPLC chromatogram 


\section{Method validation}

The method was validated in compliance with $\mathrm{ICH}\left(\mathrm{Q}_{2} \mathrm{R}_{1}\right)$. The parameters for validation are Specificity, linearity and Range, Precision, ruggedness, accuracy, robustness, stability of analytical solution and forced degradation studies.

\section{Specificity}

Specificity is the ability of assess unequivocally of analytic in the presence of components which may be expected to be present. A photodiode array detector was used for analysis of stressed solutions to determine the specificity of the method and to evaluate the homogeneity of the analyte peak. In the specificity experiment, injection of blank, impurities were prepared and injected to confirm the individual retention time $\left(\mathrm{R}_{\mathrm{t}}\right)$, resolution $\left(\mathrm{R}_{\mathrm{s}}\right)$ and tailing factor. Empower software was used to establish the Peak purity. The solutions of sorafenib and regorafenibdrug substances at specification level were prepared and injected into UPLC. The peak purity obtained was found to be acceptable (Purity angle<purity threshold) which shows that no additional peaks were co-eluting with the analytes thus proving the ability of the method to assess unequivocally the analyte of interest in the presence of any potential interference. Based on the results, it can be concluded that the developed sorafenib and regorafenib drug substances method is specific for the determination of sorafenib and regorafenib drug substances. A typical representative chromatogram of sorafenib and regorafenib drug substances is shown in the fig. 6 the specificity results were tabulated in below table 2

Table 2: Results of specificity experiment

\begin{tabular}{llll}
\hline Peak name & Retention time(Min) & RRT & Peak purity \\
\cline { 3 - 4 } & & & Purity angle \\
\hline Sorafenib & 3.058 & 0.95 & 0.221 \\
Regorafenib & 3.192 & 1 & 0.45 \\
\hline
\end{tabular}

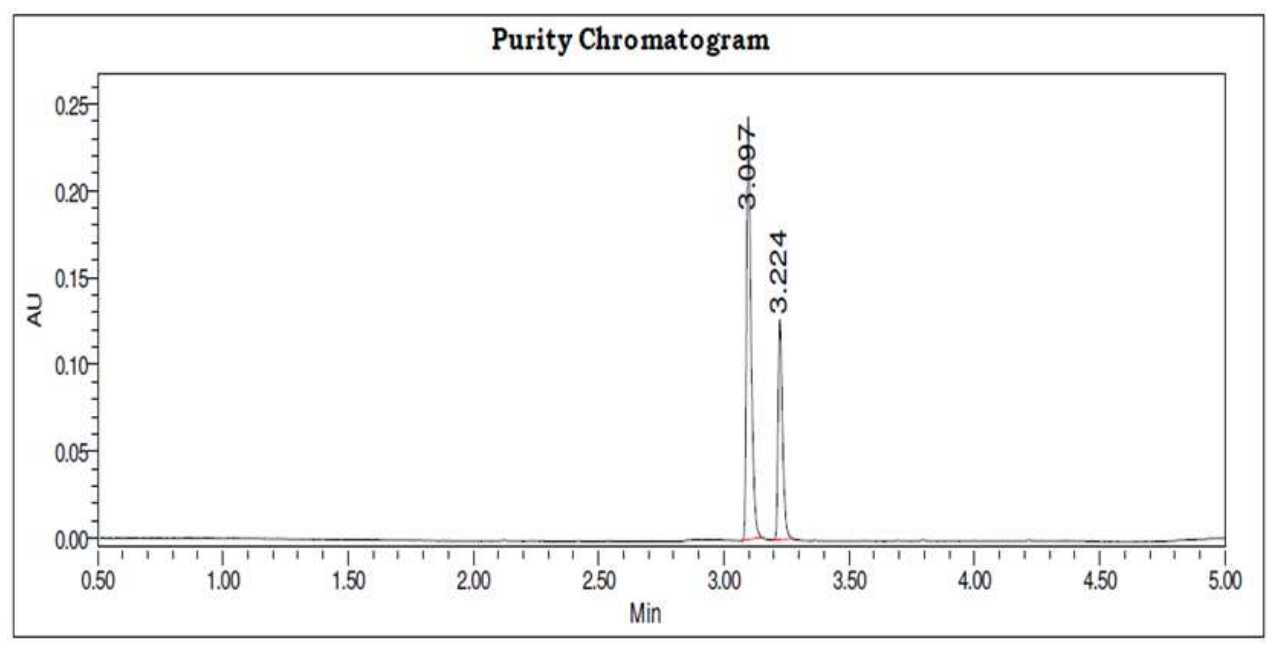

Fig. 6: Typical representative chromatogram of specificity sorafenib and regorafenib drug substances

\section{Limit of detection and limit of quantification}

The LOD and LOQ for the drug substances of sorafenib andregorafenib were determined by signal-to-noise ratio method, by injecting in triplicate series of diluted solutions with known concentrations over a range starting from $10 \%$ to $120 \%$ of the specified limit concentration of the drug substances. LOD and LOQ were obtained by plotting linearity graph of average area at each level against the concentration (ppm) and determined the slope. Chromatograms of this experiment were shown in fig. 7

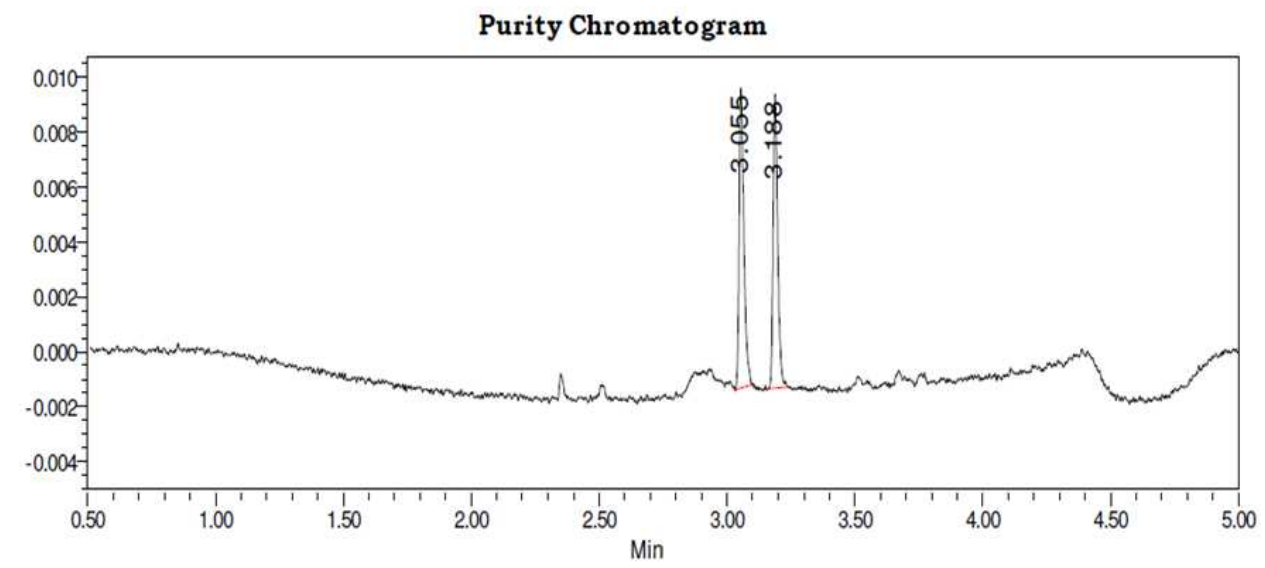

Fig. 7: Typical representative chromatogram of LOD and LOQ of sorafenib and regorafenib drug substances 
Table 3: Results of LOD and LOQ of sorafenib and regorafenib drug substances

\begin{tabular}{lll}
\hline Drug name & Sorafenib & Regorafenib \\
\hline RT & 3.055 & 3.188 \\
Area & 14185 & 13307 \\
\% & 51.60 & 48.40 \\
Purity angle & 6.629 & 6.922 \\
Purity Threshold & 7.703 & 8.303 \\
USP Resolution & & $3.815146 \mathrm{e}+000$ \\
USP Tailing & $1.531729 \mathrm{e}+000$ & $1.359137 \mathrm{e}+000$ \\
s/n & 10.113095 & 9.902502 \\
\hline
\end{tabular}

\section{Linearity}

In this linearity parameter, a series of solutions were prepared using sorafenib and regorafenib drug substances at varies concentration levels of specification level and each solution was injected and calculated the statistical values like slope, intercept, STDV and correlation coefficient from linearity plot drawn for concentration and peak area. A plot area of the peak as a function of analyte concentration was prepared and its regression equation computed. The statistical values were tabulated in below table and linearity plots of these drug substances were shown in fig. 8 and the results were tabulated in the table 4 .

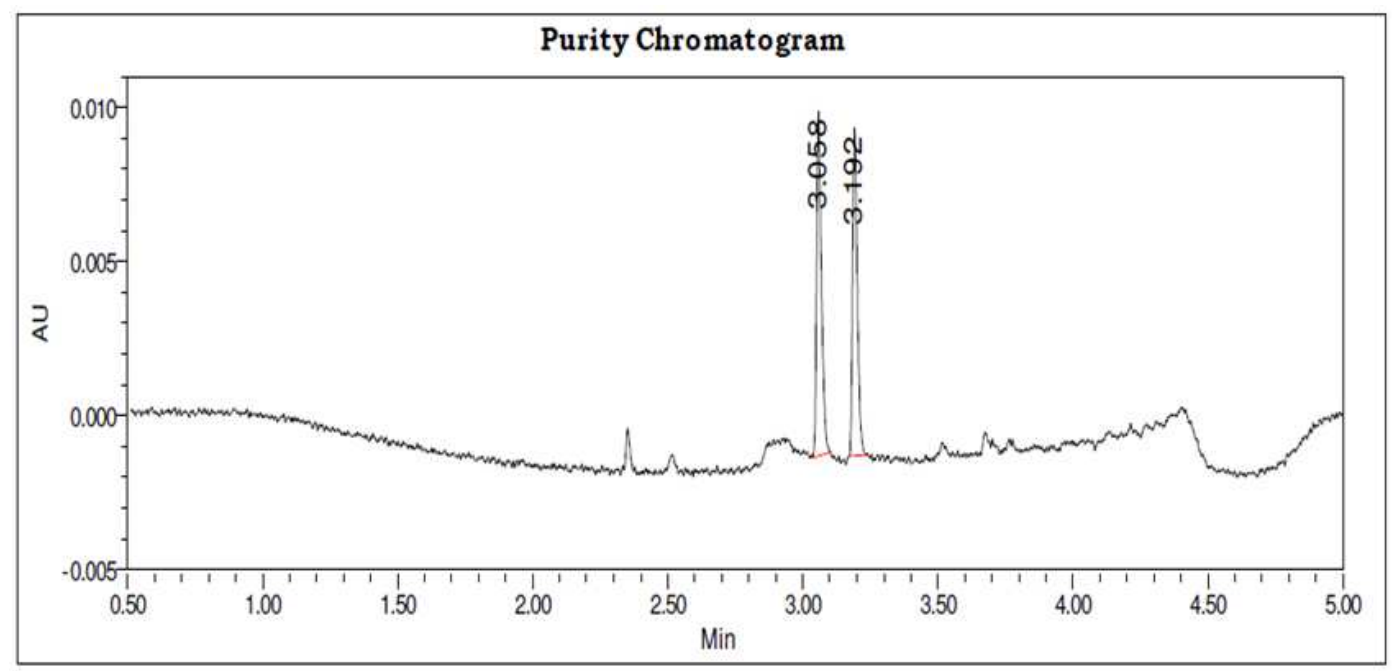

Fig. 8: Typical representative chromatogram of LOD and LOQ of sorafenib and regorafenib drug substances

Table 4: Statistical results of linearity

\begin{tabular}{|c|c|c|c|c|}
\hline \multirow[t]{2}{*}{ Linearity level } & \multicolumn{2}{|l|}{ Sorafenib } & \multicolumn{2}{|l|}{ Regorafenib } \\
\hline & Conc. $(\mu \mathrm{g} / \mathrm{ml})$ & Mean peak area & Conc. $(\mu \mathrm{g} / \mathrm{ml})$ & Mean peak area \\
\hline 1 & 1.3 & 14243 & 0.35 & 13341.5 \\
\hline 2 & 4 & 65617 & 1.6 & 38731 \\
\hline 3 & 8 & 142912 & 3.2 & 76459.5 \\
\hline 4 & 12 & 253453 & 4.8 & 127044 \\
\hline 5 & 16 & 311538 & 6.4 & 154297 \\
\hline 6 & 20 & 398028 & 8 & 192568.5 \\
\hline 7 & 24 & 481917 & 9.6 & 247323 \\
\hline Correlation coefficient & & 0.99 & & 0.99 \\
\hline Intercept & & 15243 & & 1245.2 \\
\hline Slope & & 53206 & & 10064 \\
\hline
\end{tabular}

\section{Precision and ruggedness}

In the precision study, the precision (System precision) was evaluated by injecting six injections of sorafenib andregorafenib drug substances and calculating the \% RSD. The \% RSD was determined for peak areas of sorafenib andregorafenib drug substances and the acceptance limits should be not more than $2 \%$ and the results were found to be within the acceptance limits. In the method precision also six injections of sorafenib andregorafenib drug substances were prepared as per analytical method by spiking at limit level and compared with one unspiked sample. The \% RSD for method precision was calculated. Results of the precision were presented in table 5.

\section{Accuracy}

Accuracy of the method was determined by standard addition method by spiking known drug substances in sale preparation. The $\%$ recovery of sorafenib and regorafenib drug substances at different levels was evaluated. The $\%$ limit of recovery should be in range of $98-102 \%$ the limits obtained for sorafenib and regorafenib drug substances were found to be within the limits. Hence the proposed method was found to be accurate. The accuracy studies sows \% recover of the sorafenib andregorafenib drug substances and the limit of recovery of drug substances were $98-102 \%$ and from the above results its indicates that the method was accurate and also revealed that the commonly used excipients present in the 
pharmaceutical information do not interfere in the proposed method. The accuracy results were summarized in the below table 6 .

\section{Robustness}

In this parameter, the robustness of the method, experimental conditions were deliberately changed and evaluate system suitability requirement as per methodology. For this validation experiment, system suitability solution and sample solution spiked with sorafenib andregorafenib drug substances at specification level were prepared as per test method and injected into UPLC. To study the effect of flow rate, $10 \%$ variation $( \pm 0.1)$ flow rate was changed. The effect of column temperature was studied by keeping $25 \mathrm{c}$ and 35 c instead of 30c. Detection wave length $( \pm 3 \mathrm{~nm})$ and organic in mobile phase $( \pm 2 \%$ absolute in gradient composition) have been verified and the results obtained from these experiments are summarized in the below table 7 .

Table 5: Statistical results of precision

\begin{tabular}{lll}
\hline Injection No. & Peak area of sorafenib & Peak area of regorafenib \\
\hline 1 & 330636 & 156895 \\
2 & 332203 & 158309 \\
3 & 330464 & 158309 \\
4 & 332878 & 155737 \\
5 & 330636 & 156895 \\
Mean & 331363.4 & 157229 \\
\%RSD & 1102.96 & 1093.386 \\
\end{tabular}

Table 6: Statistical results of accuracy

\begin{tabular}{llll}
\hline Name of the drug substance & \% Level & Amount added & Amount found \\
\hline Sorafenib & 50 & 8.1 & 7.99 \\
& 100 & 16.15 & 16.25 \\
Regorafenib & 150 & 24.2 & 24.12 \\
& 50 & 3.21 & 3.19 \\
& 100 & 6.42 & 6.45 \\
\hline
\end{tabular}

Table 7: Statistical results of robustness

\begin{tabular}{|c|c|c|c|c|c|c|c|}
\hline \multirow[t]{2}{*}{ Condition } & \multirow[t]{2}{*}{ Variation } & \multicolumn{6}{|c|}{ System suitability } \\
\hline & & Sorafenib & & & Regorafenib & & \\
\hline STP & & USP Resolution & USP Plate count & USP Tailing & USP Resolution & USP Plate count & USP Tailing \\
\hline Flow & $0.4 \mathrm{ml}$ & & 148220 & 1.48 & 4.0 & 137536 & 1.37 \\
\hline Flow & $0.5 \mathrm{ml}$ & & 151426 & 1.48 & 3.9 & 169121 & 1.37 \\
\hline Flow & $0.6 \mathrm{ml}$ & & 157535 & 1.47 & 4.0 & 204407 & 1.39 \\
\hline
\end{tabular}

\section{Forced degradation studies}

\section{Acid hydrolysis}

Acid decomposition was carried out in 1N HCL at concentration of 1PPM Sorafenib and Regorafenib after refluxation for 24hours at $80^{\circ} \mathrm{c}$, the stressed sample was cooled, neutralized and diluted as per requirement with diluents filtered and injected. The resulting chromatogram is shown in fig. 3 . The results are tabulated in table 3.

\section{Base hydrolysis}

Base decomposition was carried out in $1 \mathrm{~N} \mathrm{NaOH}$ at concentration of $1 \mathrm{PPM}$ Sorafenib and Regorafenib after refluxation for $24 \mathrm{~h}$ at $80^{\circ} \mathrm{C}$, the stressed sample was cooled, neutralized and diluted as per requirement with diluents filtered and injected.

\section{Oxidation}

Oxidation was conducted by using 3\% Hydrogen peroxide solution at room temperature for 24hours at 1PPM conc of Sorafenib and Regorafenib.

\section{Temperature stress studies}

$400 \mathrm{mg}$ of Sorafenib and $160 \mathrm{mg}$ Regorafenib sample was taken into a petridishand kept in oven at $80^{\circ} \mathrm{C}$ for 2days. $1 \mathrm{mg}$ of sample was taken into $100 \mathrm{ml}$ flask diluted volume with diluent, further $1 \mathrm{ml}$ to $50 \mathrm{ml}$ made up with diluent.

\section{Photo stability}

$400 \mathrm{mg}$ of Sorafenib and $160 \mathrm{mg}$ Regorafenibwas taken in to a petridish and kept in photo stability chamber $200 \mathrm{~W} . \mathrm{hr} / \mathrm{m} 2$ in UV
Fluorescent light and 1.2M LUX Fluorescent light. $1 \mathrm{mg}$ of sample was taken into $100 \mathrm{ml}$ flask diluted volume with diluent, further 1 $\mathrm{ml}$ to $50 \mathrm{ml}$ made up with diluent.

\section{CONCLUSION}

In pharmaceutical formulations, the impurities and degradation products can change the pharmacological and toxicological potency of the active pharmaceutical ingredient which has adverse effect on quality, safety and efficacy of the drug. In the present study, a rapid, precise, specific and stability indicating RP-UPLC Method was developed. The proposed RP-UPLC method for the simultaneous quantification of sorafenib andregorafenib drug substances was validated and found to be applicable for routine quantitative analysis of sorafenib and regorafenib drug substances. The results of linearity, precision accuracy and specificity were proved to be within the limits. Therefore, this method can be employed in routine analysis for simultaneous estimation of sorafenib andregorafenib drug substances in quality formulations and dissolution studies.

\section{ABBREVIATION}

RP-UPLC-Reverse-Phase Ultra-Performance Liquid Chromatographic method, LOD-Limit of Detection, LOQ-Limit of Quantification, ICH-International Conference on Harmonization guidelines, RG-Regorafenib, SFB-Sorafenib, M2-regorafenib-N-oxide, M5-N-desmethyl-regorafenib-N-oxide,M7-regorafenib-N- $\beta$ glucuronide, Rt-Retention Time, $\mathrm{R}_{\mathrm{s}}-$ Resolution.

\section{ACKNOWLEDGEMENT}

The authors acknowledge to department of Engineering chemistry, AUCE (A), A. U. for providing general lab facilities, technical support 
and for providing TEQIP phase III fellowship. This work was supported by University Grants Commission-National Fellowship for Scheduled Caste.

\section{FUNDING}

Nil

\section{AUTHORS CONTRIBUTIONS}

All the author has contributed equally.

\section{CONFLICT OF INTERESTS}

Declared none

\section{REFERENCES}

1. Anticancer drug; 2018. Available from: https://www.britannica.com/science/anticancer-drug. [Last accessed on 03 Dec 2019]

2. Hayden EC. Cutting off cancer's supply lines. Nature 2009;458:68697.

3. Song T, Liang Y, Cao Z, Du W, Li Y. Computational analysis of specific micro RNA biomarkers for noninvasive early cancer detection. Hindawi Bio Med Res Int 2017;2017:1-9.

4. Corrie PG, Pippa G. Cytotoxic chemotherapy: clinical aspects. Medicine 2008;36:24-8.

5. Anand P, Kunnumakkara AB, Sundaram C, Harikumar KB, Tharakan ST, Lai OS, et al. Cancer is a preventable disease that requires major lifestyle changes. Pharma Res 2008;25:2097-116.

6. Rampling R, James A, Papanastassiou V. The present and future management of malignant brain tumours: surgery, radiotherapy, chemotherapy. J Neurol Neurosurgery Psychiatry 2004;75 Suppl 2:24-30.

7. Kim S, Yazici YD, Calzada G, Wang ZY, Younes MN, Jasser SA, et al. Sorafenib inhibits the angiogenesis and growth of orthotopic anaplastic thyroid carcinoma xenografts in nude mice. Mol Cancer Ther 2007;6:1785-92.

8. Coriat R, Nicco C, Chereau C, Mir O, Alexandre J, Ropert S, et al. Sorafenib-induced hepatocellular carcinoma cell death depends on reactive oxygen species production in vitro and in vivo. Mol Cancer Ther 2012;11:2284-93.

9. Borthakur G, Kantarjian H, Ravandi F, Zhang W, Konopleva M, Wright JJ, et al. Phase I study of sorafenib in patients with refractory or relapsed acute leukemias. Haematologica 2011;96:62-8.

10. Huang L, Li G, Zhu J, Li Z, Li T, Leng X. Efficacy of sorafenib after liver transplantation in patients with primary hepatic carcinoma exceeding the Milan criteria: a preliminary study. Onco Targets Ther 2012;5:457-62.

11. Mross K, Frost A, Steinbild S, Hedbom S, Buchert M, Fasol U, et al. A phase i dose-escalation study of regorafenib (BAY 734506), an inhibitor of oncogenic, angiogenic, and stromal kinases, in patients with advanced solid tumors. Clin Cancer Res 2012;18:2658-67.

12. Crona DJ, Keisler MD, Walko CM. Regorafenib: a novel multitargeted tyrosine kinase inhibitor for colorectal cancer and gastrointestinal stromal tumors. Annals Pharmacother 2013;47:1685-96.

13. Strumberg D, Scheulen ME, Schultheis B, Richly H, Frost A Buchert M, et al. Regorafenib (BAY 73-4506) in advanced colorectal cancer: a phase I study. Br J Cancer 2012;106:1722-7.

14. Strumberg D, Schultheis B. Regorafenib for cancer. Expert Opin Invest Drugs 2012;21:879-89.

15. Tlemsani C, Huillard O, Arrondeau J, Pascaline BR, Cessot A, Blanchet B, et al. Effect of glucuronidation on transport and tissue accumulation of tyrosine kinase inhibitors: consequences for the clinical management of sorafenib and regorafenib. Expert Opin Drug Metab Toxicol 2015;11:785-94. 